\title{
Many Questions and Few Answers: On Conversion in English
}

Salvador Valera Hernández

Universidad de Jaén

\begin{abstract}
Conversion is a well-known word-formation process which, a priori, seems relatively easy to identify. However, a close look at its basics brings to light some critical questions which still remain unanswered to this day. The very nature of this operation, and the concepts of full and partial conversion are therefore here examined in the light of a need for explicit criteria for recognition of actual cases of conversion. Evidence supporting this need is supplied by a review of a variety of processes which have the same results as conversion when they operate on English adjectives and adverbs.
\end{abstract}

\section{Introduction}

Conversion is customarily understood as "... the change in the part of speech of a form without any overt affix marking the change" (Bauer Introducing Linguistic Morphology 241); as such, it has traditionally been regarded as particularly widespread in English in comparison with other languages or with other word-formation processes (see, for example, Kruisinga $A$ Handbook III 478, Biese 6, Zandvoort 265, Bauer English WordFormation 226, Huddleston 23, Quirk et al. 1558, Tournier 169, or Kastovsky 199). Other definitions of conversion do not substantially differ from this; in fact, a bibliographical review of some of its major descriptions will invariably run along similar lines as the ones above (Sweet I 38-40, Jespersen Modern English Grammar VI 85, Biese 6, Robertson 20506, Bryant 340-41, Zandvoort 265, Adams 16, Potter 162-63, Bauer English WordFormation 32, Huddleston 23, Quirk et al. 1558, Tournier 169, Kastovsky 181, or Lipka 85-86). 
The virtual unanimity in the definition of this concept is, however, not paralleled by the actual term given to it. "Conversion," "functional shift," "zero-derivation," and several variants of these have at one or the other time competed to name this process. Such different terms as the above are only the result of various perspectives from which the same process can be contemplated, and arguments for and against every one of them can be accordingly found. Thus, for example, "functional shift" is preferred in some references because it readily mirrors the adoption of new syntactic capacities by converted units. Explicit as this term is from the syntactic point of view, it also has to be admitted that, as pointed out by Tournier (169), it rather overlooks the complete lack of change in the derivational morphology of the word that is proper to conversion, while focusing on a syntactic property common to other parallel but still clearly different word-formation processes like, for example, suffixation. An opposite view is apparently held by other authors, who prefer to use the term "zero-derivation" instead, thus laying emphasis on the morphological dimension of the process, i.e., indicating that no morphological variation occurs under this operation and, by contrast, somehow overshadowing the new syntactic capacities of these units. This latter term has been particularly widespread, probably because it parallels other word-formation patterns which involve word-class change and thus fits an orderly structure of word-formation processes (Lipka 86).

However, the most frequent term for this operation has clearly been "conversion." Certain objections to it have sometimes been raised, for example, by Adams, who rejects this term on the grounds that it may be understood, rather than as the adoption of new syntactic capacities, as implying a complete loss of the original identity of the word, like in the noun stimulant, nowadays hardly an adjective (16). Similarly, as pointed out by Lipka, it has sometimes also been proposed that the use of the term "conversion" be avoided in strictly synchronic approaches (85). However, current practice shows that, more often than not, this term occurs regardless of any diachronic consideration, for example, in Quirk et al., where the description of conversion focuses on its nature as a wordformation process and any historical implication is explicitly disregarded (1558). One way or the other, all these terms coincide in describing the operation by which a lexical unit gains access to syntactic functions habitually realized by members of a word-class different than the one to which that unit originally belonged, like in the following examples, where nouns become verbs, and verbs become nouns respectively:

(1) Mr Wallace immediately faxed a letter which was delivered by hand to the Reporter, asking for one hour extra to be allowed.'

(2) However, Professor John Gunn, who chaired the working party which recommended the construction of Nina in 1960 said that the delay was inevitable because of the financial constraints at the time.

(3) On our more active days, when we had a go at volleyball or windsurfing at the beach, we were always ready for the 4 o'clock 'after beach' party at the poolside where the animation team served coffee, cakes and liqueurs at special prices ....

(4) He told himself that all men were cowards when it came to a showdown with a woman. 
Unlike suffixation, syntactic extension in conversion occurs without any morphological alteration of the original lexical unit, or with only some well-known minor variations, like voicing of the final consonant, shift of stress, or replacement of some consonant in the orthography. These changes, however, do not involve any systematic affixation and units affected by them are, on these grounds, still liable to a reading in terms of conversion (Bauer English Word-Formation 228-29, Quirk et al. 1566-67, Kastovsky 200), although perhaps only of a specific subclass ("quasi-conversion" in Tournier 174). In the cases in which adoption of new morphological inflections foreign to the original word-class of the converted unit but in complete agreement with the newly acquired syntactic functions takes place, morphological variation is not an obstacle to acknowledgement of conversion. Rather on the contrary, such morphological variation has been interpreted as a sign that the lexical unit in question has been entirely converted to a new member of a different word-class ("complete," "total" or "full conversion"). By contrast, when only syntactic (not morphological) attributes are adopted, it is then preferable to talk about "partial conversion."2

\section{Preliminary remarks. The nature of conversion}

There are several questions in relation to conversion which, to the best of our knowledge, have for a long time remained open despite the efforts made to settle them. Such is the case, for example, of the question whether conversion involves creation of a new word, i.e., whether the result of conversion is one or two words or lexemes (see Robertson 206, Huddleston 23, 106, Kastovsky 181, or Lipka 86), or also, at least for some authors, the identification of the base and the derived form in the process of conversion. This latter issue was extensively studied by Marchand ("On a Question" and "A Set of Criteria") and has later been discussed in several other references (Leech 224-25, Adams 38 et passim, Potter 168-69, Huddleston 24, Quirk et al. 1558-59, Tournier 177-78, Cruse 133, Kastovsky 199, or Lipka 85-86). Our attention will be centred, however, on a more basic feature of conversion, and also on one where answers are found to be somewhat lacking, namely, the importance of syntactic considerations for acceptation of conversion.

As mentioned above, extension of the functional potential of a particular lexical unit beyond the limits of its word-class is an essential requirement of conversion. However, it is not completely clear to what extent such syntactic extension should involve a change of word-class, i.e., to what extent conversion consists in the adoption of syntactic functions proper to a word-class different from that to which the lexical unit originally belonged. Certainly, even though change of word-class is so frequent that it is often deemed as a hallmark of conversion, some other authors, like Leech (215-16) or Quirk et al. (1563 et passim) also allow for conversion of a secondary kind when the changes in the grammatical attributes of a lexical unit do not exceed the limits of one word-class, for example, when an uncountable noun allows for countable reference, a non-gradable adjective admits gradation, or when a typically intransitive verb enters a transitive structure (for an opposite view of some of these examples, i.e. examples interpreted as 
cases of secondary conversion, see Bauer English Word-Formation 227-28 or Huddleston 107):

(5) India's economic failure is not the cause of the hatred between its religions, but it makes the hatreds worse.

(6) ... and the sooner he could recommend that Quince be transferred to somewhere more metropolitan, where robbery with violence might occur, the happier Bramble would be.

(7) In such situations, it is always worth considering whether it is safer to have another launch and $f y$ the glider to the hangar.

But a more important question than this is, however, the fact that occurrence of conversion in English should be judged on the grounds of a correlation, that between word-classes and syntactic functions, which is far from being a precise one. Thus, for example, it is difficult to say to what extent premodification of the head of a noun phrase by a noun, like in stone age or iron monger, should be considered to overstep the limits of the functional potential of the word-class noun and fall within the limits of the wordclass adjective, or to what extent out and around should be accepted as prepositions actually converted to adverbs in the following examples by Quirk et al. (715):

(8) She went out.

(9) There were lots of people around.

These examples lead to discussions like those which will be reviewed below in relation with partial conversion (see section 2.2.). For the moment, and taking into account all these considerations, what seems evident is that the process known as conversion basically consists in the extension of the functional potential of lexical units, i.e., is primarily recognised on the grounds of syntactic evidence, and is also one in which the role of morphology limits itself to remaining unchanged or, in some other cases, to serving as evidence of full conversion. Thus, even though conversion responds to a particular morphosyntactic profile where both the morphological and syntactic behaviour of converted units are of primary importance for its acknowledgment, it seems clear that the dimension of the lexical unit on which conversion operates is essentially the syntactic one, in other words, rather than a morphological process, conversion is a syntactic one. A proof of this is the fact that, except for the new syntactic functions, there is but little to describe in converted units and, if anything at all, it is certainly not their derivational morphology, which, by definition, does not vary at all or does so only insignificantly.

Whereas still a word-formation process, review of conversion in view of these considerations thus suggests that terms like "zero-derivation" mentioned above and which have a distinct morphological import, or, more clearly, overt classifications of conversion as a morphological process or terms like "morphological conversion" in Huddleston (2324) are not entirely appropriate in so far as they lay undue emphasis on the role of (derivational) morphology in this process. 


\subsection{On full conversion}

In the introductory section, a distinction was advanced between two different types of conversion, "full" and "partial." Such a distinction, which has not always been observed, as can be seen from the references cited in endnote 5 by comparison to those in endnote 2, appears to us as remarkably difficult to apply in English on a systematic, sound basis. Following the references cited in endnote 5, full conversion is said to occur when the converted lexical units adopt not only some of the syntactic functions of a particular wordclass, but also its inflectional morphology, since adoption of the morphological marks of a given word-class in addition to its syntactic ones is interpreted as a further stage in the acquisition of properties of a different word-class by comparison with the mere adoption of syntactic properties of partial conversion illustrated in the second example of each of the following pairs:

(10) Hoards of young fans descend in files through the traffic, their legs scissoring the dusty car beams into shafts of ever-changing swirls of marbled light.

(11) These come in many styles but are basically of two types - those where the blades pass each other in a scissor action, and those where a single sharp blade presses down on a block or 'anvil'.

(12) President Roosevelt wired Churchill on 21 November that both sides had compromised, but the UK insisted on restricting the number of aircraft irrespective of the amount of traffic ....

(13) The houses were neat and not unpleasing in design, though to Winnie's eyes they appeared to be built far too close together, and the low wire fences gave no privacy.

(14) Wycliffe browsed among the second-hands. Along with scores of authors of whom he had never heard, he found forgotten friends.

(15) It is extraordinary that many more people have an inspection when buying a secondhand car than they do when purchasing a house.

Yet, such a distinction between full and partial conversion, however easy to identify may it render the former, seems slightly inappropriate to us for several reasons. Firstly, because it relies on a strictly morphological criterion, namely, adoption of the inflections of a particular word-class, which appears hardly adequate for a language in which wordclass inflections have become gradually blurred since the Middle English period and which are nowadays systematically present in very few categories. And secondly, because semantic variation has often been neglected as evidence for the distinction of full vs. partial conversion, thus focusing basically on two aspects of words, their morphology and their syntax, while somewhat ignoring semantic considerations which, as we will later see under section 4, may be of, at least, the same importance. A description of English along the traditional lines above may thus successfully deal with cases of full conversion involving the word-classes noun and verb, as these still retain some significant inflections, but will invariably find itself at a loss when studying conversion between word-classes which, like adjectives, adverbs, conjunctions and prepositions may or will never take any inflection: 
(16) I was living in Mayfair and was just about to move from there and buy my first flat. (17) These things all took time but now I must say that, for me, it is just about perfect. (18) Anyway perhaps if if [sic] I come back to you after next Tuesday afternoon when I've got a meeting to talk just about that subject with the deputy and see what options are going to come forward.

(19) Today, each person with AIDS is surviving on average longer than two years, needing more care than ever before.

(20) Owen, seven years younger, was killed one week before the war ended.

(21) The cube should be thoroughly sterilised and rinsed before use.

A similar case can be observed, for example, in alleged cases of conversion from adjectives to adverbs or vice versa, where full conversion as understood above can never be documented in so far as adoption of the inflection of the new word-class, in this case, inflection for degree, may not render the converted lexical units morphologically different as some adjectives and units of adjectival character, like participles, tend to express comparative and superlative degree by means of the periphrastic construction with more and most and, at any rate, adjectives and adverbs share the same inflection for degree and, consequently, make full conversion difficult to ascertain: ${ }^{3}$

(22) That tradition was later eschewed by later republicans.

(23) Gettrude Stein later wrote a book on Picasso, in which she put the point like this: ....

(24) This pattern of cultural change is one of the clearest indications of the powerful impact that dominant social attitudes and values have on the status and treatment of older people.

(25) This newsreader speaks clearest of all. ${ }^{4}$

It could well be said, then, not only that full conversion as traditionally described can be documented only in those word-classes of English in which systematic inflection still remains active but, what is more important, that it can only be acknowledged in cases involving word-classes whose inflections still allow for discrimination on strictly morphological grounds. As we can see, therefore, the notion of full conversion in English seems to have been tailor-made largely for two or, at the most, three word-classes, noun, verb and adjective. This should hardly be a surprise, as it is these word-classes, especially the former two, that provide the most frequent (or perhaps only the most conspicuous) patterns of conversion in English (Potter 168, Adams 38, or Quirk et al. 1560). However, this same concept of full conversion ignores some other cases like conversion between adjectives and adverbs, which do not differ in their inflectional morphology or, simply, may not take inflections systematically:

(26) For a long time it has been known that heavy drinking during pregnancy can badly affect a baby's development so that when it is born, its face and head are deformed and it is mentally backward.

(27) With her extended white cloud of frizzed hair she has been a constant, if sometimes startling, presence in the New York underground art scene for many a year. 
The result is that, under the current standards of the description, in the case of the adverbs and prepositions as well as in the case of adjectives and adverbs, full and partial conversion cannot be distinguished unless on grounds other than the morphological or syntactic ones. Certainly, it would not be possible to conclude whether backward and underground in the examples above are cases of full or of partial conversion, firstly because they can always realize functions proper to adjectives and adverbs and can thus be ascribed on a syntactic basis to two different word-classes, which in any case does not discriminate between full and partial conversion; and, secondly, because even if they adopted the inflection of the new word-class, their inflectional morphology would never substantially vary from one word-class to another. On these grounds, therefore, they would necessarily have to be accepted as cases of partial conversion and, this, in view of their semantics, seems rather unsatisfactory.

\subsection{On partial conversion}

In contrast with full conversion, partial conversion involves adoption of only some of the properties of a different word-class, usually of a syntactic type, so that partially converted units add to their characteristic functional potential other functions which are regularly realized by members of various word-classes. In other words, under partial conversion, in comparison with full conversion, lexical units do not take any new morphological inflections while realizing syntactic functions characteristically ascribed to several of them. As partially converted units therefore do not incorporate any of the inflections of the wordclass which normally realizes the newly-adopted syntactic functions, a feeling prevails in these cases that they belong to several word-classes at the same time, or that they can partake of the properties of two word-classes at the same time (see Sweet I 39, Zandvoort 266 , or Tournier 195). This view, which is only one of the many possible ones in relation with partially converted units, is however illustrative of the close relation that partial conversion bears with the limits between word-classes and which probably led Adams to affirm that "partial conversion is a term descriptive of certain kinds of syntactic behaviour, the limited overlapping of the classes" (19). This is certainly our point of view too, especially considering that partial conversion as described in the references consulted for this paper is invoked only in relation with two very specific types of structures, namely, those in which adjectives appear to be the head of a noun phrase, and those in which a noun premodifies another noun, like in the following examples: 5

(28) The Spanish expelled the Muslims from the island, but were not able to bring it under their full control, or defend its inhabitants from Muslim raiders until nearly the end of the nineteenth century.

(29) The homeless are being asked to gather at the Commonwealth Hall.

(30) He is suffering from an ankle injury and a virus infection.

(31) As I looked through the viewer I had the feeling, momentarily, that it really was what I had dreamed about for so long, a sort of crystal ball in which I could call up everything I had ever known. 
It was already advanced in section 2 that the correspondence between word-classes and syntactic functions in English is far from being a close one not only because members of one word-class may realize functions which are distinctive of a different one, but also because the same syntactic function may be realized by members of different classes. Actually, the limits between the traditional classes of words in English are known to be particularly indistinct, possibly as a result of the influence of conversion, as has sometimes been claimed (in this latter respect, see Robertson 206 and Bryant 255, 341).

It is our belief, however, that to allow for the existence of such a concept as partial conversion (especially if this applies only to very few cases), and to say that the limits between word-classes in English are not clear-cut is to give two different answers to the same question of certain realizations of syntactic functions. Certainly, we often come across particular cases which, like the above mentioned virus infection and crystal ball in (30) and (31), can be explained either in terms of partial conversion but also in terms of the unclear limits between the functional potential of the word-classes noun and adjective. To give the former analysis only to some examples, the latter to a few others, and then say that conversion blurs the limits between word-classes is as tempting a position as it is unsatisfactory.

Examples like the above with Spanish and homeless in (28) and (29) on the one hand, and virus and crystal in (30) and (31) on the other, where the lexical units in bold type would a priori be assumed to belong to a given word-class (adjective and noun respectively for each pair of examples), but actually realize functions commonly associated with a different one (noun and adjective respectively), have often been the object of discussion. It is certainly possible to consider these as instances of partial conversion, and such has been the view of some descriptions (Sweet I 39, Robertson 209, Bryant 341, Zandvoort 266, or Potter 167; for several authorities along the same lines, see also Marchand Categories and Types 360$)^{6}$. It would no doubt be interesting to pursue here the question why full conversion (instead of partial one) could not be equally accepted in these examples: whereas in the first two cases it is certainly true that Spanish and homeless do not take the inflection for number as most nouns would in that example, the argument that virus and crystal are not fully converted to adjectives because they cannot take predicative position, because they cannot inflect for degree or for any other similar reason intended as a defining feature of adjectives would seriously have to contend, respectively, with the high number of adjectives which cannot take predicative position at all, which do not inflect for degree or are just non-gradable, or which somehow differ from the central type of adjectives and are nonetheless wholly accepted as adjectives too (on a number of criteria of this type and their use as a criterion for recognition of conversion, see Zandvoort 275, Bauer English Word-Formation 228, Huddleston 328, or Quirk et al. 1562).

However, what really matters at this point of our study is that, whereas examples like (28) to (31) have been sometimes described as conversion, some other authors dismiss such an interpretation for cases of this kind and instead contemplate them as the result of processes of a syntactic or lexical nature, or of some kind of ellipsis (Marchand Categories and Types 60-61, Bauer English Word-Formation 227-28, Huddleston 107-08, 325-28, or Quirk et al. 421-24, 1559). Certainly, all four examples could be described equally well without resorting to the notion of conversion, in particular, in the former two examples as 
a case of ellipsis of the head of a noun phrase as explained in many other similar instances, and in the latter two in terms of complex nominals resulting from the application of a "recoverable predication deletion rule" (Levi 75-77). In this latter case in particular, several studies on premodification in the noun phrase have clearly shown that the origin of premodifiers realized by nouns or by the so-called "transpositional" (Marchand Categories and Types 229), "denominal" (Coates 160) or "nonpredicate" adjectives (Levi 16-17) lies in a number of structural variants of an underlying pattern from which certain constituents are promoted to the surface position of premodifier. Consider thus nouns or the above mentioned non-predicate adjectives related to their modified heads through one or the other "recoverably deletable predicate" described by Levi, namely, cause, have, make, use, be, in, for, from, and about (76-77):

(32) Here, too, were knick-knacks and glossy magazines stolen from some of the other rooms: a leather belt with a carved brass buckle that shone like gold when polished with a cloth, a brooch set with brilliant red and yellow stones, an airman's badge, a pen-knife, a fountain pen.

(32a) [a belt made of leather with a carved buckle made of brass]

(33) An event takes place on May Day at Ilkley that has no connection with tree spirits, water spirits or indeed any springtime rites or festivals.

(33a) [any rites or festivals in springtime]

(34) As I write there are a few small, unexcited newspaper reports about the progress of peace talks taking place, under the aegis of ex-President Jimmy Carter, in Atlanta, Georgia.

(34a) [the progress of talks about peace].

An interpretation of these premodifiers as partially converted to members of the wordclass adjective would no doubt account for their surface syntax, but would also ignore the processes underlying this structure of premodification and, consequently, the syntactic and semantic relations that they maintain with their modified heads (Coates 167). Thus, both perspectives, one overtly referred to conversion and the other discarding it, are at present still maintained despite the fact that, firstly, it has been observed that many cases usually accepted as conversion actually are but the result of ellipsis (Marchand Categories and Types 360-61), and, secondly, that premodification of nouns by other nouns can be successfully explained in accordance with a number of well-defined patterns from an underlying structure.

\section{Adjectives, adverbs, and the question of single forms with several syntactic functions}

Marchand's remark in the last few lines of the previous section brings up the issue of the various processes whose effect on the lexical units on which they operate is the same as that of conversion, that is, whose effect is the association of one morphological structure 
with syntactic functions characteristically realized by members of several word-classes, either by extension of their functional potential while leaving their morphological structure unaltered, or by neutralization of the distinctive morphological marks. This section reviews some morphological, syntactic and lexico-semantic processes which have been dealt with elsewhere in relation with the so-called relation of homomorphy (see Quirk et al. 70-71, 405-09 or Valera). These processes are relevant here in so far as their operation on adjectives and/or adverbs results in the association of one morphological structure with syntactic functions which belong to the functional potential of both word-classes, just as conversion would. Actually, our previous research on a sample corpus of adjective/adverb homomorphs proved not only that, contrary to what had been previously assumed, the role of conversion in homomorphy was of much lesser importance than initially suggested in Quirk et al. (70-71), but also that a discrimination of conversion from these other processes was in many cases both possible and advisable. The following can then be understood as a brief review of cases in which a reading of conversion has been made of adjective/adverb homomorphs which actually can (and, for us, should) be explained on quite different grounds than those of word-formation.

Perhaps one of the most significant of such processes involves neutralization of the original morphological marks of adjectives and adverbs over the period of Middle English. The systematic levelling and subsequent loss of many of the Old English inflections by some well-known phonetic and analogical processes neutralized the differences between the members of both word-classes, with the result that a number of adjectives and their related adverbs which could originally be distinguished from each other by means of their respective inflectional and/or derivational morphology, became morphologically identical and can at present be identified as belonging to each word-class only by their syntactic functions (Sweet I 325, 429, Jespersen Modern English Grammar III 403, Magnusson 53, Robertson 314-15, Mustanoja 1 314, 648-50, Bryant 397, 427, Marchand Categories and Types 94, Fernández 334, or Tournier 180). Convergence of syntactic functions in one morphological form is thus in many cases the result of a number of well-known diachronic processes which are therefore a distinctly separate phenomenon from conversion, and which are thus responsible for the morphological identity not only of many adjectives and adverbs, but also of other word-classes like nouns and verbs (for the distinction between these diachronic processes and conversion, see Zandvoort 265 and, especially, Tournier 179-80, or Valera 67-71; as to the operation of these processes on nouns and verbs, some of which are interpreted as cases of conversion, see Jespersen Modern English Grammar VI 86 et passim, Marchand Categories and Types 363, or Tournier 180).

A different case, also of a strictly morphological kind, is that of the deletion of the $-l y$ adverbial ending in certain varieties or registers of English (Quirk et al. 446-47, or Vermeire 149 in relation with American English; see also Kruisinga A Handbook III 114, Jespersen Modern English Grammar III 360, Zandvoort 322, Bäcklund 159, Quirk et al. 406 , or Vermeire 149 in relation with substandard register). Since these adverbs are derived from an adjectival base, loss of the suffix renders the original adverb morphologically identical with the adjective from which it was derived, while maintaining its (adverbial) syntactic behaviour. The consequence of this process invariably is the 
association of a representatively adjectival morphology with the functional potential characteristic of the word-class adverb: ${ }^{8}$

(35) The threat was enough to stop Rita and Bob going as far as their friends with real rude words.

(36) I sort of start running now to find a way out quick, but this wire fence goes all the way down to the wall at the other end....

A number of processes of an essentially syntactic nature can also be considered here. Similarly to some nouns which premodify heads of noun phrases, like the ones discussed in 2.2. above, a number of adverbs can gain access to premodification of the head of a noun phrase through some specific syntactic transformations (Jespersen Modern English Grammar II 335-37, Quirk et al. 453, Kastovsky 189, or Valera 134-35):

(37) The confessional and moral attitudes were largely the work of the constitution's architect, the then prime minister Eamon de Valera.

(37a) [the person that was then president]

(38) Conditions to be met are that the employee must be enrolled for at least one academic year with actual full-time attendance to average at least 20 weeks, and the rate of payments ... must not exceed $£ 7,000$ a year or the equivalent monthly or weekly rate. (38a) [the rate that is paid monthly or weekly].

Here, like in the case of premodification by nouns, an interpretation of these adverbs as converted to adjectives would satisfactorily account for these particular syntactic structures, but would also overlook the fact that, even in these positions, such lexical units still maintain the same syntactic and semantic relationships as they have in any other position in which they are unmistakably accepted as adverbs. An interpretation of then in (37) as an adverb converted to an adjective in the above examples would probably be difficult to accept even for those who admit conversion in other similar cases like virus or crystal in (30) and (31) respectively. But the case of then also has some other far-reaching implications. Certainly, objections to the acceptation of premodifying then as an adverb converted to an adjective make equally unacceptable the acknowledgment of, for example, monthly or weekly as adjectives just because of their capacity to premodify heads of noun phrases. This is especially so considering that, as in the case of then, their adjectival behaviour only consists in this type of premodification, and their -ly ending cannot be explained as a modern form of the original Old English adjectival suffix -licc. Certainly, the suffixes $-l i \bar{c}$ and -lice of Old English adjectives and adverbs became neutralized into one single form over the period of Middle English. This explains why -ly, which is the current form of these two endings, can occur both in adjectives and adverbs. However, whereas in some lexical units in -ly of Modern English like deadly, kindly or yearly both the adjectival and the adverbial forms can be traced back in etymological dictionaries, in some other cases, like monthly or weekly, the same morphological distinction cannot be documented. Consequently, when the adjectival dimension of these latter units consists only in premodification of heads of noun phrases, the case is not substantially different from that of premodifying then and, therefore, a reading of conversion is equally difficult 
to sustain however tempting it may seem to interpret all cases in -ly identically (on the evolution and the nature of the modern suffix -ly, see Jespersen Language 377, Nist 190 91, or Guimier).

As to postmodification of heads of noun phrases by adverbs, there seems to be general agreement on the idea that, rather than a case of conversion, in these cases we face ellipsis of the subject and predicator of postmodifying relative clauses whose clause pattern is typically of the type SPA: ${ }^{9}$

(39) Mr Sweet does not want to farm the site, but dig it up for the valuable peat underneath.

(40) A pair of collared doves were moaning in the trees overhead; ....

Similarly, deletion of the head of a prepositional phrase is also responsible for the acceptation as adverbs of nouns and compounds of a nominal origin (Bresnan \& Grimshaw 347 et passim, Quirk et al. 556-57, 692-95, Emonds, or McCawley; for a different view of the same question, see Larson):

(41) Environment Secretary Mr Howard was travelling first-class between his Folkestone constituency and Ashford in Kent when he faced the embarrassing showdown two weeks ago.

(41a) [was travelling by first-class]

(42) Many bands have taken on a style of clothes which they bought second-hand.

(42a) [which they bought at second-hand].

Certainly, after deletion of the preposition, the adverbial function originally realized by a prepositional phrase becomes identified with the remaining noun phrase, with the result that what originally was only a noun (or noun phrase) governed by a preposition, may become associated with the word-class adverb and be eventually accepted as such. Why conversion has been invoked for this latter type of formations (for example, in Bryant 341 ) and not for the former can only be explained, for us, in terms of the greater difficulty in recovering the deleted elements in this latter case. Finally, at least two different semantic processes can be identified as the origin of new syntactic functions in certain adjectives/adverbs. In the first case, repeated use of adjectives hyperbolically marking the degree of a given state in certain fixed lexical sequences eventually became acceptable for combination in other different unrestricted sequences in this other case simply expressing degree and devoid of their expected lexical meanings to varying extents (see Bäcklund 229-31):

(43) Anyway, at last I got absolutely blind drunk through depression, went upstairs to Freda's bedroom and cried myself to sleep.

(44) I was really, really tired, I was dead tired....

Similarly, it is also well-known that repeated occurrence of premodifiers of the head of a noun phrase with no punctuation mark between them eventually gave rise to an interpretation of the former of these as a premodifier of the following modifier rather than 
as a premodifier of the nominal head (Jespersen Modern English Grammar II 366 et passim, Bolinger 24-25, or Bäcklund 13, 132-33, 161; see also Kruisinga A Handbook IV 119-20):

(45) We can now mix species to create whole new animals that nature never intended.

(46) It's a very funny joke, but it works at the expense of treating her like a child, which is not at all what the novel usually intends. ${ }^{10}$

The opposite process takes place in adverbs which, by metaphorical extension of their literal meaning, expand their semantic load in a direction in which they no longer convey a meaning of time or place location (as is usually the case), but one of a state or condition instead and, accordingly, realize functions like subject complement or modifier of the head of a noun phrase, just as many adjectives do (Jespersen Modern English Grammar III 396, 402, Quirk et al. 733, or Valera 97 et passim):

(47) It is an ideal place for a honeymoon but life afterwards must seem all downhill, at least in terms of location.

(48) People who are behind with their electricity bills could find themselves restricted to a consumption of as little as one kilowatt.

\section{Conclusions}

Conversion, then, very much like word-classes in English, is apparently easy to recognise in broad lines, but difficult to identify with accuracy. Firstly, because it seems more appropriate not to maintain the distinction between full and partial conversion, especially if the former is of a rather limited application among word-classes and if the latter takes place only in two very specific cases (and even more so if these can be successfully explained without resorting to the notion of conversion at all). Those cases in which converted units adopt new inflections could then be simply taken as instances of conversion in which not only syntax, but also morphology indicates the change of wordclass. Adoption of marks signalling the new word-class at the morphological, syntactic and/or semantic levels can thus be interpreted merely as evidence of varying degrees of acceptation of one particular unit as a member of a new word-class, but not as a requisite for a special case of conversion. This view is not substantially different from Huddleston's, in so far as it does not consider, for example, premodification of nouns by nouns a case of partial conversion, but it is clearly divergent as no major differences are drawn here between converted lexical units which adopt new inflections, and those which do not, simply because there are not any available for the particular word-class involved in the functional shift (106-08). The second reason why conversion seems a complex concept is that a review of the processes outlined under 3 above leads to the conclusion that, if these processes have anything in common, it is, firstly, that their effect on the lexical units on which they operate is the same as that of conversion and, secondly, that, despite this similarity, they do not bear any relation to lexical need or with what should literally be 
understood as word-formation. And yet, the description of morphological, syntactic, or semantic operations like the ones above has often interpreted the units affected by these as cases of conversion, or has implicitly or explicitly invoked conversion as the cause of these changes (Sweet I 69, 118-19, 125, Jespersen Essentials 73; Modern English Grammar VI 84-85, Biese 9, Robertson 209, Bryant 341, Zandvoort 276, Potter 168, 175, Quirk et al. 1560, Tournier 194, or Vermeire 148).

For us, however, only in the case of the lexico-semantic processes above could a reading of conversion be sustained, and this on the grounds that the base form is substantially different from the derived one, as can be seen not only from their syntax but also from their semantics. ${ }^{11}$ Units like downhill or behind in (47) and (48) here have a figurative meaning which is a metaphorical extension of a previously existing literal one. Derivation of such figurative meaning triggers access to syntactic functions that in many cases remained inaccessible to the literal one and which are a syntactic parallel to semantic divergence from the original. Such marked differences as can be appreciated between the syntax and semantics of both cases, the literal and the figurative, can thus be taken as a sign that they have certainly come to form part of a different word-class in one more respect. Certainly, occurrence of properties of two different word-classes, adjective and adverb, can be clearly observed by contrasting the nature of the syntactico-semantic relationship held by the literal and by the figurative term in one same structure of premodification, intensive in the former case (SPC), circumstantial (SPA) in the latter:

(49) His biggest problem was always behavioural and emotional, resulting from his frustration at being treated as a difficult or educationally backward child.

(50) New GCSE examinations represent a backward step by right-wing Tories towards the school tests of the 1950s, a union official claims.

(51) Two Afghans, among several arrested trying to cross the border, 'admitted that they belonged to an intelligence group entrusted with the organisation of an underground antiSoviet movement in Tadjikistan, whose purpose was to turn the republic into an Islamic state'.

(52) A special committec of MPs meets to decide the fate of a controversial bill under which the main line and underground stations would be transformed and a new terminal and platform built for Channel Tunnel trains.

Although conversion has often been described in terms of not only syntactic but also some semantic change, the semantic relation between the base and the derived form in usual cases of conversion is much closer and of a different kind than that between the literal and metaphorical meaning of the examples above (for a review of the semantic relationships between the base and derived forms in conversion, see Quirk et al. 1560 et passim; on semantics and conversion, see Sweet I 39, Marchand Categories and Types 359-60, Adams 27-28, Leech 215-16, or Tournier 175). When, like here, a metaphorical extension from a literal to a figurative sense can be appreciated, a case of polysemy has often been made, although the particular syntactico-semantic profile occurring in examples of this kind also has the grammatical implications typical of conversion. To our knowledge, these cases have seldom been studied, and our bibliographical review has 
revealed a considerable variation in this field. In particular, lexicographic practice ranges from treatment of converted units in different entries or in just one, as can be seen in the nouns and verbs shout or risk grouped under one same entry in the Longman Dictionary of Contemporary English. 2nd ed. London: Longman, 1989, on the one hand, while described in different entries in the Oxford Advanced Learner's Dictionary of Current English. 5th ed. Oxford: Oxford UP, 1995, on the other. In some cases, both arrangements can occur in the same dictionary, for example, the latter reference combines the noun and verb shout under one entry but presents the noun and verb show separately under two, one for each word-class (see also Huddleston 106 and Lipka 2) ${ }^{12}$ In this respect, our point of view, however elementary it may be, responds to the occurrence of two different functional potentials systematically paralleled by two different semantic loads, which would seem a solid enough basis for a reading of complete or full conversion, in this case from adverb to adjective. Lack of any morphological mark showing this is, for us, only the consequence of the lack of any different inflections between both word-classes and, consequently, unimportant as an obstacle to our reading of conversion especially in view of the evidence provided by the semantic characterization of each of the instances above.

All in all, an interpretation of conversion is sound in the particular cases of the semantic processes above in so far as the essential nature of the unit has changed syntactically as well as semantically to the extent that it no longer has any relation with the original one apart from the common origin and the morphological structure. On the contrary, a reading of the remaining cases in terms of conversion seems hard to accept.

It is then manifestly the case that what a priori could be assumed to be conversion between adjectives and adverbs, eventually turns out to be more than that, and that, consequently, extension of conversion at least in the case of these two word-classes is considerably more limited than expected. Interestingly enough, a view of relatedness with conversion is persistently maintained in some of these cases, however clear it may be that the process responsible for the morphosyntactic behaviour of particular lexical units is substantially different from conversion (see Jespersen Modern English Grammar VII 46, Biese 18, and Tournier 179-80 on levelling of inflections and conversion). Such inconsistencies probably arise from the lack of any systematic criteria for recognition of conversion, since the adoption of morphological, syntactic or semantic properties is not always satisfactory as a criterion for acceptation of conversion to a new word-class in view of the morphological, syntactic and semantic heterogeneity of members of word-classes. Some systematic criteria should then be established to discriminate conversion from other processes whose effects on the units on which they operate are the same. These criteria, which could ultimately rely on the existence of a lexical need in so far as conversion is a word-formation process, would probably discriminate real conversion from other processes which, like the ones operating on adjectives and adverbs, may have the same effects, and would, consequently, lead to a more limited view of the extension of conversion in English. The next question is how to articulate these criteria. 
1. Unless otherwise specified, all examples have been taken from the British National Corpus.

2. In the literature consulted for this paper, the difference between both types of conversion, or definitions of one or the other type of conversion along the lines mentioned in the text can be found only in Sweet (I 38-39), Zandvoort (266), Adams (19-20, 26-27), Potter (166-67), Quirk et al. (1559), and Tournier (175).

3. A similar distinction is drawn by Huddleston between bottle (noun and verb) and what (determinative and pronoun) as different cases in relation with conversion (106-08). Such a view relies on the fact that the latter lacks inflectional marks signalling the new word-class, which is then interpreted as necessarily entailing that it cannot be considered at the same level as the former.

4. Example borrowed from Quirk et al. (406).

5. Zandvoort also groups under partial conversion certain structures which, like those with adverbial superlatives, can also be looked upon as cases which do not involve conversion but some kind of ellipsis, or which, like premodification of nouns by adverbs, prepositional phrases and sentences, can be explained on similar grounds as premodification by nouns $(271-72,276)$.

6. Although still accepting Spanish and homeless in (27) and (28) as cases of conversion, Biese (334 et passim), clearly identifies ellipsis as the underlying origin of some of these constructions; see, similarly, Tournier (175-77).

7. On other occasions, existence of other keys to the creation of such adjective/adverb homomorphs, like analogy, was assumed as necessarily existing, but was not actually assessed. On this question of analogy and conversion, see Sweet (1 429-30), Kruisinga ("Contributions" 107), Jespersen (Modern English Grammar III 363), Biese (272), Robertson (317), or Tournier (183).

8. Although it is well-known that English word-classes are not morphologically marked in a consistent way, i.e., it is not always possible to identify their members on morphological grounds, these units can still be considered to be "representatively adjectival" in so far as they are systematically paralleled by an $-l y$-derived adverb.

9. In what follows, SPA stands for the clause pattern Subject-Predicator Adverbial, and SPC for Subject-Predicator-Subject Complement.

10. As explained in Jespersen (Modern English Grammar II 367-68) and Bäcklund (158) very was adopted from the French verrailverailverrey/veray and, as such, it was an adjective meaning real or true, like in the following examples:

But the very nature of advice can only be understood if we understand in what spirit it is meant to be offered and for what reasons it is meant to be taken.

Greek by nationality, he was born and spent most of his life in Russia, returning to the land of his ancestors only at the very end of his days, where he shortly thereafter died.

However, this original lexical meaning was gradually replaced by one of mere intensification (really or truly) to the extent that when it currently premodifies the head of an adjective phrase, like in the example in the text, very little of its original content can be noticed, if any at all.

11. Apart from these cases, it could also be argued that a view of conversion could be sustained in cases of -ly deletion, as it is motivated by a need for non-existing short forms, just as in many other cases of conversion. The same applies to cases when the lexical unit in particular is inflected for degree, when -ly deletion under these circumstances has been sometimes cited as not determined by any variety or register (for example, in Sweet I 131 or in Quirk et al. 406, 465). Yet, even in these cases conversion is only one of several possible hypotheses, since -ly deletion 
(or, rather, use of a representatively adjectival form instead of the corresponding adverbial one in view of examples like “. . . Don't you tell nobody what I said, or I'll fix you good. Got it?') can have an analogical basis, especially considering the widespread and stable patterns already existing in which representatively adjectival forms occur in positions usually occupied by adverbs.

12. Some descriptions liken other similar (not actually these) cases of conversion with polysemy (Huddleston 106), and with homonymy (Lipka 138, 140), the latter reference basically on the grounds that conversion involves existence of different lexemes; however, two questions should be addressed before this latter view could be definitely accepted: first, whether this syntactico-semantic characterisation actually involves two different lexemes and therefore falls beyond polysemy, and second, whether conversion really involves creation of new lexemes or not.

\section{Works cited}

Adans, Valerie. An Introduction to Modern English Word-Formation. London: Longman, 1973. Bäcklund, Ulf. The Collocation of Adverbs of Degree in English. Doctoral dissertation at Uppsala University, 1973.

Baver, Laurie. English Word-Formation. Cambridge: Cambridge UP, 1983. Introducing Linguistic Morphology. Edinburgh: Edinburgh UP, 1988.

Biese, Yrjoe M. "Origin and development of conversions in English." Annales Academiae Scientiarum Fennicae B XLV-2 (1941): 1-495.

Bolinger, Dwight L. Degree Words. The Hague: Mouton, 1972.

Bresnan, Joan and Jane Grimshaw. "The syntax of free relatives in English." Linguistic Inquiry 9 (1978): 331-91.

Bryant, Margaret M. Modern English and its Heritage. 2nd ed. New York: Macmillan, 1962.

Coates, Jennifer. "Denominal adjectives: a study in syntactic relationships between modifier and head." Lingua 27 (1971): 160-69.

Emonds, Joseph E. "The invisible category principle." Linguistic Inquiry 18 (1987): 613-32. Fernández, Francisco. Historia de la lengua inglesa. Madrid: Gredos, 1982.

Guimier, Claude. "On the Origin of the Suffix -ly." Historical Semantics. Historical Word-Formation. Ed. Jacek Fisiak. Berlin: Mouton, 1985. 155-70.

Huddleston, Rodney D. Introduction to the Grammar of English. Cambridge: Cambridge UP, 1984.

Jespersen, Otto. Essentials of English Grammar. London: Allen \& Unwin, 1933.

Language, its Nature, Development and Origin. London: Allen \& Unwin, 1922.

A Modern English Grammar on Historical Principles. London: Allen \& Unwin, 1909-49.

Kastovsky, Dieter. "Word Formation." A User's Grammar of English: Word, Sentence, Text and

Interaction. Ed. René Dirven. Frankfurt am Main: Peter Lang, 1989. 171-213.

Kruisinga, Etsko. "Contributions to English syntax. XVII: on the history of conversions in English." English Studies IX (1927): 103-08.

A Handbook of Present-Day English. 5th ed. Groningen: P. Noordhoff, 1931-32.

Larson, Richard K. "Bare-NP adverbs." Linguistic Inquiry 16 (1985): 595-621.

Leech, Geoffrey N. Semantics. Harmondsworth: Penguin, 1974.

Levi, Judith N. The Syntax and Semantics of Complex Nominals. New York: Academic Press, 1978. 
Lipka, Leonhard. An Outline of English Lexicology. Tübingen: Niemeyer, 1990.

McCawley, James D. "Adverbial NPs." Language 64 (1988): 583-90.

Magnusson, Rudolf. Studies in the Theory of the Parts of Speech. Lund: C.W.K. Gleerup, 1954. Marchand, Hans. The Categories and Types of Present-Day English Word-Formation. 2nd ed. München: C. Beck, 1969. "On a question of contrary analysis with derivationally connected but morphologically uncharacterized words." English Studies 44 (1963): 176-87. "A set of criteria for the establishing of derivational relationships between words unmarked by derivational morphemes." Indogermanische Forschungen 69 (1964): 10-19. Mustanoja, Tauno F. A Middle English Syntax. Helsinki: Société Néophilologique, 1960. Nist, John. A Structural History of English. New York: St. Martin's Press, 1966.

Potter, Simeon. Changing English. 2nd ed. London: A. Deutsch, 1975.

Quirk, Randolph, et al. A Comprehensive Grammar of the English Language. London: Longman, 1985.

Robertson, Stuart. The Development of Modern English. Ed. Frederic G. Cassidy. 2nd ed. Englewood Cliffs, New Jersey: Prentice-Hall, 1954.

Sweet, Henry. A New English Grammar. Logical and Historical. Oxford: Clarendon Press, 1891-98.

Tournier, Jean. Introduction Descriptive à la Lexicogènètique de l'Anglais Contemporain. Genève: Slaktine, 1985.

Valera, Salvador. Adjetivos y adverbios en inglés: la relación de homomorfia. Granada: Servicio de Publicaciones de la Universidad de Granada, 1996.

Vermeire, Toon. "Adverbs and Adverb Phrases." A User's Grammar of English: Word, Sentence, Text and Interaction. Ed. René Dirven. Frankfurt am Main: Peter Lang, 1989. 143-70.

Zandvoort, Reinard W. A Handbook of English Grammar. 6th ed. London: Longman, 1972. 